At the meeting of the American Astronomical Society to which reference has just been made, two other observatories reported upon their stellar parallax work. Lee and Joy of the Yerkes Observatory reported the parallaxes of nine stars with a maximum probable error of $0^{\prime \prime} .014$ and an average probable error of $0^{\prime \prime} .010$, and Mitchell, of Leander McCormick Observatory, reported the parallaxes of eleven stars with a maximum probable error of $0^{\prime \prime} .012$ and an average probable error of $0^{\prime \prime} .009$.

The progress made in the accuracy of parallax results is shown at a glance in the following table.

THE ACCURACY OF STELLAR PARALLAX DETERMINATIONS

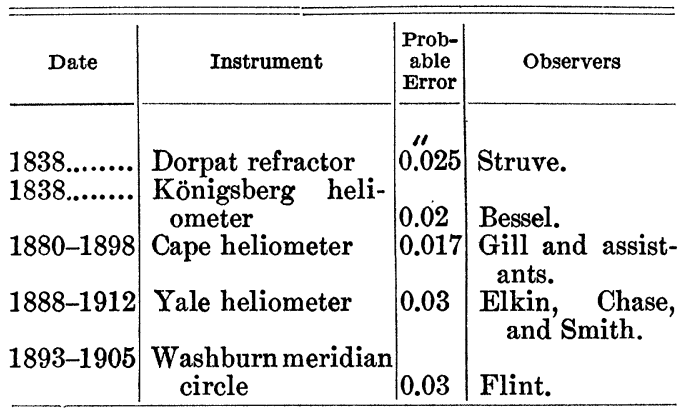

Photographic Results

\begin{tabular}{|c|c|c|c|}
\hline 1910 & Yerkes refractor & $|0.013|$ & Schlesinger. \\
\hline $1915 .$. & Yerkes refractor & 0.010 & Lee and Joy. \\
\hline $1915 \ldots$ & Leander McCor- & 0009 & Mitchell \\
\hline 1915. & $\begin{array}{l}\text { Mt. Wilson } 60 \text {-inch } \\
\text { reflector }\end{array}$ & 0.006 & Van Maanan. \\
\hline
\end{tabular}

From these results it appears that any star whose parallax is as much as $0^{\prime \prime} .02, i . e$, whose distance from the earth is less than ten million times that from the earth to the sun, should give a positive result when subjected to the treatment now employed in parallax investigations, and as eight or ten observatories are devoting their energies to stellar parallax work at present, the combined programs containing over 1,000 different stars, we ought to have soon lists of at least a few thousand stars whose parallaxes are known where our present ones contain but a few hundred.

W. S. Eichelberger

U. IS. Naval Observatory

\section{METHODS OF TEACHING ELECTRICAL ENGINEERING 1}

IN the American engineering schools must be recognized professional schools of distinctly advanced grade corresponding to the schools of the more ancient professions of medicine, law and theology. With marked sympathy for artisanship in its most useful forms, their practises and ideals are fully distinct from schools of skilled artisanship such as are in certain countries known as engineering schools; and the preparatory studies required to make students eligible to enter their courses of instruction definitely contain much work in mathematics and the sciences, in addition to an optional range of studies in the modern languages, economics and civics, history and the classics. That is, the American engineering schools are professional schools of university order, as the term university is known internationally. This form of the engineering schools in America is the result of experience and development, which has brought them to educational characteristics much resembling those of the Ecole des Ponts et Chaussees and the Ecole Polytechnique of Paris.

Originating with the third decade of the nineteenth century, the earlier American engineering schools first treated of what we now term "civil engineering," and "mechanical engineering" and "mining engineering" were later joined to the fixed curricula. It was not until 1882 that a formal course of "electrical engineering" was established, and curiously enough, this was done independently and almost

1 Pan-American Sicientific Congress, Washington, D. C., January 4, 1916. 
simultaneously in two of our most noted engineering schools, Massachusetts Institute of Technology and the engineering school of Cornell University. In each of these, the first graduates completed their courses in June, 1885. Thereafter, formal courses of instruction in electrical engineering were established in most of the educational centers supporting engineering schools, until there are now ninety-five such courses in the land, embracing over 8,000 students, and from whom over 19,000 students have graduated. These courses can not be accepted as of equal rank, but it may be reasonably claimed for all that certain methods of instruction have proved serviceable and are given more or less full acceptance, depending upon the stability and strength of the organization, and the thoroughness of preparation which may be required of entering students.

Fundamentally there are two principles lying at the root of the methods of our best engineering schools, which are:

1. It is the business of these schools to train young men into fertile and exact thinkers guided by common sense, who have a profound knowledge of natural laws and of the means for utilizing natural forces for the advantage of man and the advancement of civilization. In other words, it is the business of engineering schools to produce, not finished engineers, but young men with a great capacity for becoming engineers, the goal being attained by the graduates only after years of development in the school of life.

2. The problem facing the engineering schools is more particularly a problem of pedagogy rather than a problem of the engineering profession. The problem is how to properly train the students' powers to the stated purposes. It must be grappled with all the directness and force of the engineers' best efforts, but it can not be solved as solely relating to the engineering profession.

Turning now toward electrical engineering, it is to be observed that electrical engineering demands industrial engineers-men with an industrial training of the highest type, competent to conceive, organize and direct extended industrial enterprises of broadly varied character. These men must be keen, straightforward thinkers, who see things as they are and who are not to be misled by fancies; they must have an extended, and even profound, knowledge of natural laws (more particularly of those relating to energy and its transformations), and an extended knowledge of the useful applications of these laws; and they must be acquainted with business methods, the affairs of the business world, and with the ways of our fellow-men.

Some of our colleagues may ask "What is electrical engineering, that it demands these things of its followers?" I will answer. Electrical engineering is that branch of the profession which deals with the generation of power, primarily from fuel or water, its conversion into electrical power which may be transmitted and distributed at will for the service of the industrialist and the householder, and, for its fullest service, electrical engineering must embrace the principles and fundamental practises underlying all the great industries and activities which it serves, and it must not shirk the controlling problems of illumination. Electrical engineering is now master of the methods of national and international rapid intercommunication, of local transportation, of ready transmission of water or steam power to a distance, of a safe and convenient method of artificial illumination, and its service in the industries is constantly enlarging, but is already probably incalculable. This is a vast field of science in the industries, which brings under 
requisition the problems of mechanics, the characteristics and uses of materials and their correct application to the building of actual structures, the laws of kinematics and the processes of designing and using machinery, the special principles of hydraulics and thermodynamics and the manner in which they enter into the design, construction and operation of machines; and the manner in which they affect the usefulness of machines and the efficiencies of various industries; and it brings into association with all these the specific principles of electricity and magnetism and the ways in which these principles may be used in practise.

It is only with such definitions of the field of electrical engineering and the scope of engineering education in mind that one can truly approach a discussion of "methods" of teaching electrical engineering. Lacking such definitions, the whole connotative picture is vague, indefinite, and lacking in guide posts. Given such definitions, the problem obtains definiteness and reasonable precision. The word method then may be applied. These definitions or ideals are therefore fundamental to this address. With them as guides the word "method" has a meaning and leads directly to the proposition that electrical engineering instruction must be bilateral in character, dealing first with processes of direct logic applied in mathematical forms to the solution of problems, and second with processes of reasoning by balance of evidence such as are characteristic of the discussion of economic principles or historical sequences. These two processes of reasoning hold nearly equal importance in electrical engineering, in which respect this branch of engineering differs widely from, for instance, mechanical engineering, in 'which a great part of the mental processes of its practitioners must be by balance of evi- dence because the problems are commonly of a complexity which has not yet yielded to methods of rational analysis, thus leaving empirical methods the only resort. Thus, the design of a cast-iron bed for a great engine lathe deals with a material of unhomogeneous character which is put under tension, compression and shear, in a physical shape for which the stresses do not yield directly to mathematical analysis on account of the complexity of the form which is imposed by the requirements of convenience in operating the complete machine. In contrast to this, most of the engineering problems which relate purely to electricity and magnetism partake of the character of problems of' hydrodynamics and yield directly to rational processes of analysis, $i$.e., to assault by direct logic. In electrical engineering teaching, it is largely the aconomic aspects of the problems, or the problems coming in from the collateral branches of engineering on account of the intimacy with which the electrical engineer must deal with the numerous branches of mechanical industry, which call for empirical methods and reasoning by balance of evidence. These are important, and therefore the methods of teaching in electrical engineering must be bilateral, as already said, first to give the student power in direct reasoning and in designing by so-called "rational" processes, and second to give him power in reasoning by balance of evidence and in designing by so-called "empirical" processes. Along with this goes hand in hand instruction of the student in nature's laws and their relations to each other, and instruction in the applications of the methods of reasoning to minor but none the less truly engineering problems. The laboratory is a living force in such instruction, and in it the student must be substantially thrown on his own resources to execute the tests or investigations assigned to him, or 
much of the merit of the instruction is lost. It is obvious that in carrying out the meth. ods of instruction here laid down, mathematics, chemistry, physics and applied mechanics are central components of the curriculum; but history and economics have an important part.

Highly developed powers of observation and induction go far to develop a man's success in electrical engineering, as in most other professional branches, and also in those branches of business that are of leading moment. This is a collateral reason why chemistry, physics, mathematics and applied mechanics are such important studies for electrical engineers. They teach their sane followers to observe closely and accurately and to draw correct conclusions from the observed premises. But an industrial engineer must also have broadly humanistic sentiments and sympathies, and he must be prepared to reason by balance of evidence from imperfect premises. These things being facts of every-day observation, what humanistic studies can we rightfully exclude from the list useful as preparation for engineering professional life, and what methods of teaching can we exclude provided only that they are directed to the teaching of the principles of science and their applications, and do not resort mainly to descriptive processes? Our solicitude need only be exercised to see that sufficient of the mathematical and physical sciences, the historical and economic studies, and the languages make constituent parts of the curriculum; and that the spirit and order in which these are studied is right. The sciences, historical and economic studies, and languages are well represented in the curricula of many of our engineering schools, but there is still a failure to impress on the students' minds that the economic subjects are intimately related with the work of the profession.
Most American engineering schools have undergraduate curricula of four years' duration. To these come large numbers of young men from the high schools and fitting schools, mostly from seventeen to nineteen years of age. They are commonly well equipped with physical vigor and latent mental strength, but they have not yet reached mental maturity. They can not be plunged without loss into a position of complete self-reliance in their processes of study, but commonly profit from a guiding hand which shows the way to self-reliance. It is only after a couple of years of the vigorous life of the engineering schools that our American young men can profit fully by laboratory work where they are thrown mostly upon their own resources; but, having reached this stage, their progress in self-reliance and effectiveness for solving minor engineering problems go hand in hand under the stimulus of a liberal method exercised by the teachers. The more mature graduates of colleges of arts gain an equal independence and effectiveness in less time.

Bringing into the midst of such laboratory classes the additional stimulus of professional research carried on by postgraduate students who are candidates for higher degrees (Master of Science and Doctor of Engineering) and by paid research assistants, as is done in the electrical engineering laboratories of the Massachusetts Institute of Technology, introduces a final factor of pedagogical method that bids fair to make the experiment an ideal success. This plan is there coupled with the classification of students, without reflection on any, in groups according to their powers, so that the quickest to assimilate may go forward as rapidly as their powers permit, absorbing collateral matter by the way, while the slower to assimilate may cover all necessary ground at a pace which affords them 
adequate thoroughness. The test of such methods by time, in the American engineering schools, is not yet complete. Indeed the last steps are quite young in our practise; but they stand high by a priori tests, and the few years' trial thus far made indicates an ideal result from the interassociation in the same laboratory of the undergraduate laboratory instruction by problems and the postgraduate laboratory research.

\section{Dugald C. JACKSON}

Massachusetts Institute OF TECHNOLOGY

\section{THE JOSEPH A. HOLMES SAFETY ASSOCIATION}

Mention has already been made in the columns of SCIENCE of the movement to start a memorial to the late Dr. Joseph A. Holmes and an account of the preliminary meeting of representatives of different national associations was given in the same article. ${ }^{1}$

The first meeting of the permanent association was held in the U. S. Bureau of Mines, Washington, on March 4 last. The following organizations were represented:

American Institute of Mining Engineers, Hennen Jennings.

American Mining Congress, Dr. David T. Day.

American Federation of Labor, A. E. Holder.

Mining and Metallurgical Society, Dr. George Otis Smith.

American Society of Mechanical Engineers, General W. H. Bixby.

American Institute of Electrical Engineers, John H. Finney.

American Electro-Chemical Society, Dr. F. G. Cottrel.

American Association for the Advancement of Science, Dr. L. O. Howard.

American Chemical Society, S. S. Voorhees.

Geological Society of America, Dr. Joseph Hyde Pratt.

National Academy of Sciences, Dr. David White.

American Red Cross Society, Dr. Robert U. Patterson.

Western Federation of Miners, Joseph D. Cannon. Mine Inspectors Institute, J. W. Paul.

1 See SCIENCE, Vol. XLIII., No. 1101, February 4, 1916, pp. 164-165.
Society for the Promotion of Engineering Education, Professor O. P. Hood' (vice Professor Wadsworth).

Letters of regret were received from the following:

United Mine Workers of America, William Green. National Safety Council, H. M. Wilson.

American Forestry Association, P. Risdale.

American Society of Testing Materials, A. W. Gibbs.

The permanent organization was effected under the name of the Joseph A. Holmes Safety Association and the following officers were elected:

President, the Chief of the U. S. Bureau of Mines (Mr. Manning).

First Vice-president, the Secretary of the Smithsonian Institution (Dr. Walcott).

Second Vice-president, the President of the American Federation of Labor (Mr. Gompers).

The members of the executive committee to serve with the other officers were elected as follows :

Mr. Hennen Jennings, representing the American

Institute of Mining Engineers.

Dr. John A. Brashear, of Pittsburgh.

The present functions of the association were formulated as follows:

1. That annually the association shall make one or more awards with honorariums to be known as "The Holmes Award" for the encouragement of those originating, developing and installing the most efficient safety devices, appliances or methods, in the mining, quarrying, metallurgical and mineral industries during the previous year, these awards to be the result of reports and investigations made by the secretary and the representatives of the association.

2. From time to time the association shall also make suitable awards for personal heroism or distinguished service or the saving of life in any branch of the mining, quarrying, metallurgical and mineral industries.

3. Once a year a meeting of the association shall be held in the eity of Washington at which all awards will be publicly announced.

\section{CONVOCATION WEEK MEETING AND THE AMERICAN CHEMICAL SOCIETY}

THE council of the American Chemical Society has by a vote of 61 to 31 declined to 